\title{
MONITORING AND CONDITION ASSESSMENT OF TRAMWAY TRACK USING IN-SERVICE VEHICLE
}

\author{
Ákos VINKó \\ Department of Highway and Railway Engineering, Faculty of Civil Engineering \\ Budapest University of Technology and Economics, Müegyetem rkp. 3 \\ H-1111 Budapest, Hungary, e-mail: vinko.akos@epito.bme.hu
}

Received 1 January 2016; accepted 21 June 2016

\begin{abstract}
A uniform track condition assessment model, which is based on both visual inspection and automatic under load track geometry measuring system, is needed to reduce maintenance cost and increase safety and ride comfort for passengers. A tramway track condition assessment model as well as a geographical information system are worked out by the Author (implementation in progress) for Budapest tram lines to detect and predict rail defects and plan the effective maintenance work. The developing method determines the track condition on the basis of visual inspection and in-service vehicle's wheels-mounted accelerometers.
\end{abstract}

Keywords: Tramway track condition assessment, Rail defects, In-service vehicle, Wheel mounted inertial sensors, Geographical information system, Visual observation, Wheel-set dynamics

\section{Introduction}

In addition to visual inspection, mostly the under load track geometry and vehicle dynamics measuring systems are used to determine the technical state of tracks in the European rail networks [1], [2]. The under load condition monitoring of tramway tracks is not widespread. On the one hand the reason for this may be the applied lower operation speed and axle load in tramway operation, on the other hand the higher safety factor of tramway tracks. So the specialists consider the visual inspection based condition monitoring to be sufficient to plan the maintenance work.

The automatic under load condition monitoring of tramway's track has not been applied in Hungary due to the lack of track recording car [3]. Although there exists available method and equipment [1], [4], [5], which can measure the geometric 
parameters of the track in unloaded state, but in most cases this is not sufficient to obtain a realistic view of real conditions of the track. The model to be introduced is based on in-service vehicle's wheels-mounted accelerometers, which ensure the under loading track measurements.

Budapest has an extended tram network, where significant reconstruction and development works are being made currently. There is no decision support system for specialists of Budapest Public Transport Ltd. (BKV), which can help the planning of the maintenance work. The developing methodology will make the track maintenance more efficient based on approximate estimation of the track technical state [6].

\section{Tramway track condition assessment}

A Tramway Track Condition Assessment Model (TTCAM) based on visual inspection and vehicle dynamics measurements as well as Geographical Information System (GIS) are worked out by the Author (implementation in progress) for Budapest tram lines. The purpose of this system is to translate the data from the inspections into a meaningful numerical quality index, which realistically characterizes the technical state of the inspected track section. However, wide variety of tramway track structure is applied to the urban guided transport due to limiting factors of the urban environment, so it is necessary to identify the easily measurable track parameters to create condition quality index irrespective of track type. Selection of these parameters is made by statistical evaluation of large number of geometry measurements of track. It is needed to store the measured data in a GIS system in order to analyze and to predict the future determination.

A database is built by the Author, which consists in the alignment data of tramway track, track types and their structural elements, track defect types and the hierarchical tram line network of Budapest.

In Fig. 1 the stored characteristic information of tram line 49 can be seen. Dynamic segmentation [7] ensures to transform linearly referenced data in database into features that can be displayed and analyzed on a map. The stored information describes the structural elements of track sections and specifies the observed and the measured track defects.

\subsection{GIS and online failure registration form}

A GIS for defining geo-referenced defect locations, storing attribute data, and displaying data on maps, is worked out by the Author (implementation in progress) for Budapest tram lines. An online failure registration form is part of this GIS system, which ensures the easily location-based data recording of the observed and measured failures for track inspectors. The form has three parts: the identification of defect location, the selection of track type, moreover, specifying the type and the form of defect as track structural components. Defect localization (step 1) is made by specifying track by traffic direction, defective track sections, or using GPS coordinates from geotagged photos. Identification of track type (step 2) is on the basis of pre-recorded data in the database, which includes the applied tramway track structures in Budapest. After defect localization and identification of track type, the observed defects of the structural 
elements can be specified (step 3). The defect types are also stored in the database, but they can be clarified and supplemented based on the practical experiences.

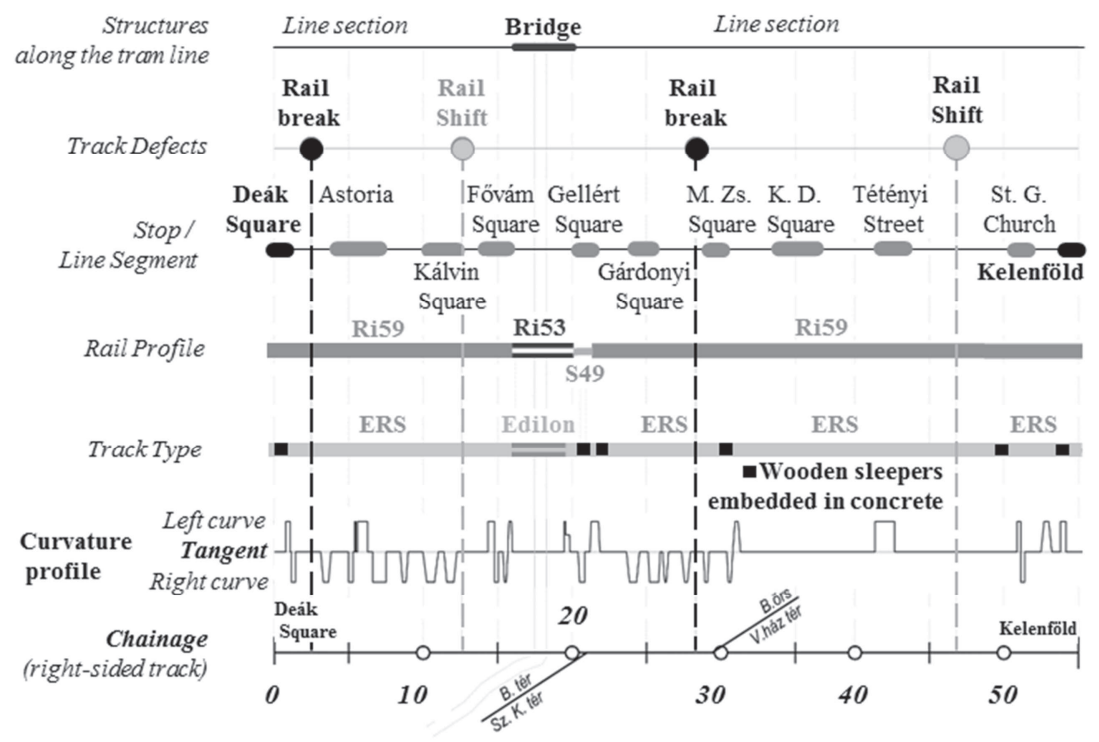

Fig. 1. The stored characteristic information in the database: Budapest, tram line 49 (Tramline chainage markers per 100 meters)

\subsection{The investigated tramcar and track}

In order to detect rail defect or predict failures, the tram track and the vehicle should be analyzed together, because the deterioration of track is a self-exciting cyclical process determined by the interaction of the vehicle, the track and the substructure [8], [9], [10], [11]. In order to understand the causes of defects, it is essential to know the mechanical equipment, the dynamic driving/braking characteristics and the running stability limits of the vehicles mainly in connection with the traction and braking systems.

The GANZ type 8 rigid-axle articulated tramcar, which does not have slip protection and torque control of the traction-motors was used for the test. It has a semi-automatic drum starter, which reduces the adverse results of the sudden starts. The powered wheel-sets are situated at both ends of the vehicle. The drum-brake is located on the driven wheel-sets, and the disc-brake are mounted the not-driven wheel-sets. Furthermore, a separate traction-motor drives two wheel-sets in the driven bogies. These two traction-motors are parallel-connected in a bogie and the bogies can be connected in parallel and in series. There is an on-tram monitoring recorder on the first driven axle. This device records angular speed, distance and time together with various customer specified signals from motor current, voltage, brake pressure, whistle, moving direction, brake activation, etc. [12], [13].

The line test was performed in operation along the Budapest tram line 49, which is one of the most frequented lines in the downtown. Along this tram line different track types can be found. The significant part of the track is grooved rail formed Embedded 
Rail Fastening System (ERFS), but in sharp curves, on the bridge and on turnouts there are special track structures.

\section{Methodology}

The TTCAM has two independent data sources. One part of the data is the observed defects of visual inspections, which are recorded into the above mentioned online failure registration form (refer to Section 2.1). The other basic element of the system is the vehicle dynamics measurements. The rail sections containing defects can be determined by using data of wheel mounted inertial sensors, because the additional load coming from irregular wheel-set motion can cause real defects in the track due to the cyclically repeated load.

Data of track geometry measuring device with electromechanical sensors and visual observation were used for validation of these defective rail sections. The validation is based on collecting characteristics of the measured data of the existing track defects [14].

\subsection{Vehicle dynamics measurements and experimental arrangement}

Digital USB 3-axis accelerometers have been used for the vehicle dynamic measurements. Only two instruments are available this time, so the accelerometers are mounted only on the not-driven-wheels. The investigated conical tramway wheelset is rigid and free, so it does not have additional loads from traction.

A steel plate provides fixing accelerometers on the wheel (see Fig. 2). It has two conical structured spacers (see cross-sectional view B-B in Fig. 2), which fit into the two bore-holes of wheel disc. These spacers expand and get stuck in the hole for torsion. The holes on the steel plate provide fixing the accelerometers by using cable tie. The longitudinal axis of the accelerometers is perpendicular to the wheel radius, so the instrument measures the tangential, radial and axial acceleration (see Fig. 2).

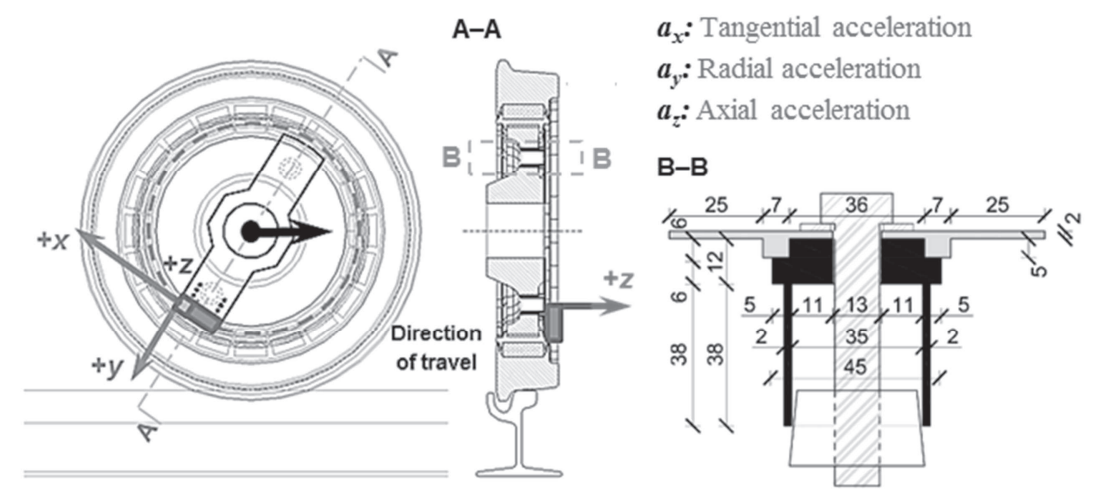

Fig. 2. Experimental set-up: the sensing directions and the conical structured spacer of steel plate 


\subsection{Determining defective rail sections based on vehicle dynamics measurement}

Basically two groups of defective rail sections can be distinguished. There are defects, which have already been formed in a visually perceptible manner and other defects, which are not directly visible. The first category includes the rail wear, surface defects and rail fractures, which result in a cyclic stress tiring. Those defective rail sections, which are not directly visible, can become real defects in the future due to the cyclical load emerging between the wheel and rail.

The possible defective rail section can be determined by data of wheel mounted accelerometers. The axial acceleration $\left(a_{z}\right)$ pointing outward from plane of wheels is suitable to detect dynamic loads emerged between the wheel flange and the rail as a short impulse. The tangential $\left(a_{x}\right)$ and radial acceleration $\left(a_{y}\right)$ is able to detect additional loads forming in the vertical plan. So the peak values in the measured signals can give information on irregular vehicle motions, which can lead track defects.

However, in some cases (if the velocity is constant) irregularities of track can be detected from the acceleration data directly without signal processing of the measured data. If the vehicle does not run at a constant speed - the frequency content of the acceleration process changes - it is necessary to use signal processing to detect track irregularities [15], [16], [17]. Various methods were used to determine the peak values in the measured signal by the Author [18].

\subsection{Localization of track irregularities}

Localization of the peak values can be achieved by data given by a wheel mounted accelerometer, using Extended Kalman-Filter (EKF). This method [19], [20] in the case of an appropriate chosen physical model is suitable to compute not measured vehicle parameters from the measured data $\left(a_{x}, a_{y}\right)$. Fig. $3 b$ illustrates the measured radial acceleration in the case of non-driven wheel. Fig. $3 a$ shows the computed parameters (using EKF): the covered distance $\left(p_{i}\right)$ and the vehicle velocity $\left(v_{i}\right)$.

EKF is a generic sensor fusion algorithm for non-linear state estimation. In the case of rolling without slip the state equations of EKF is according to [20]:

$$
\begin{aligned}
& a_{x}=-g \sin \theta+\ddot{p} \cos \theta-\frac{r_{s}}{r_{w}} \ddot{p}=-g \sin \frac{p}{r_{w}}+a \cos \frac{p}{r_{w}}-\frac{r_{s}}{r_{w}} a, \\
& a_{y}=-g \cos \theta-\ddot{p} \sin \theta-\frac{r_{s}}{r_{w}^{2}} \dot{p}^{2}=-g \cos \frac{p}{r_{w}}-a \sin \frac{p}{r_{w}}-\frac{r_{s}}{r_{w}^{2}} v^{2},
\end{aligned}
$$

where $\theta$ is the angle of rotation; $g$ is the acceleration of gravity $\left[\mathrm{m} / \mathrm{s}^{2}\right] ; r_{s}$ is the radius of inertial sensor on the wheel $[\mathrm{m}] ; p$ is the covered distance $[\mathrm{m}] ; v$ is the vehicle velocity $[\mathrm{m} / \mathrm{s}]$ and $a$ is the vehicle acceleration $\left[\mathrm{m} / \mathrm{s}^{2}\right]$.

Fig. $3 c$ shows the residual noise component of signal $a_{y}$ without radial acceleration. Using a high-pass filter [21] the reduced radial acceleration can be computed, where the cut-off frequency is determined from the maximum vehicle velocity. 

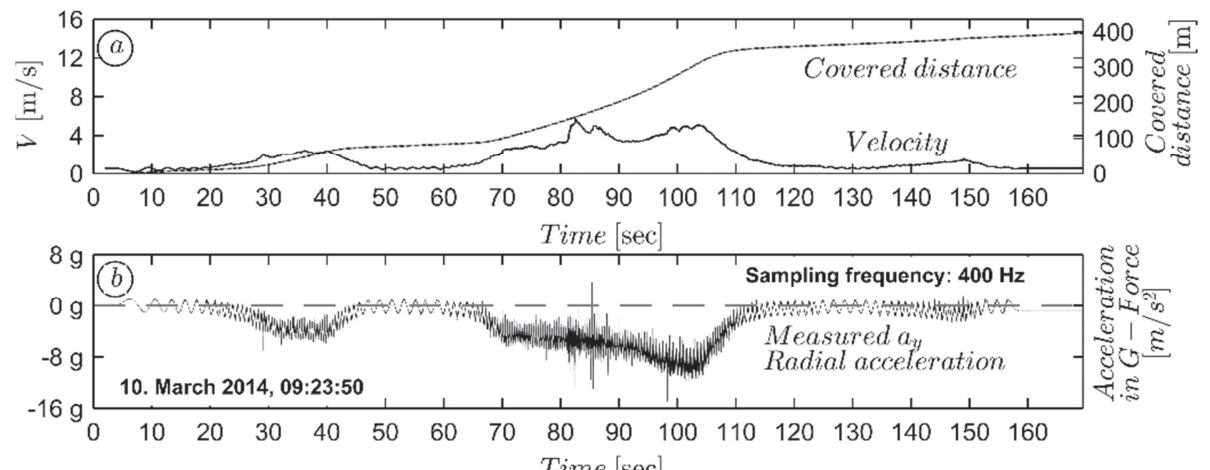

Time [sec]

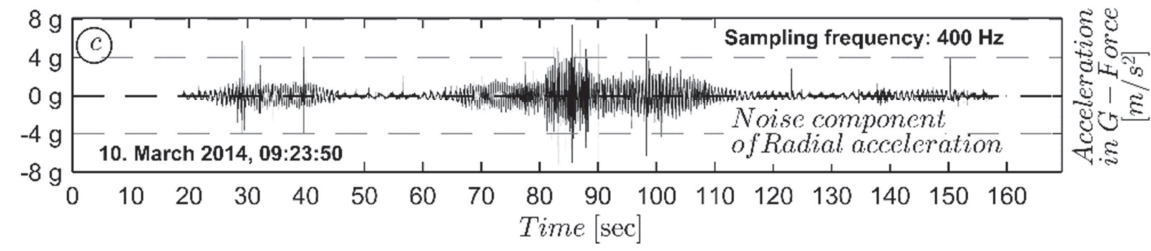

Fig. 3. a) The computed parameters: covered distance and vehicle velocity;

b) the measured radial acceleration $a_{y}$;

c) the 'noise' part of signal $a_{y}$ without radial acceleration

Extended Kalman-Filter has the advantage that the physical model is easily extendable and other sensor data can be used in the model for the measuring results clarification. The location of the defects can be identified based on the covered distance by EKF model, which can be corrected by using data of GPS sensor or on-tram monitoring recorder data.

\section{Estimated track parameters}

It should be noted that the above method detects only the defective track sections and not gives exact value of the track parameters. This measurement system only ensures estimating the following track parameters:

\subsection{Rail wear and tear}

Rail wear can be estimated by detecting forced starting and stopping of the vehicle. The occurrence of wheel slips assigns those places on track, where the rail wear can become significant due to the repeated slipping.

The magnitude and the location of wheel slip can be computed from the 'prestarting' and 'post-stopping' angle differences of the accelerometer positions on different wheels [18]. 


\subsection{Track irregularities}

The irregular vehicle motion (forced starting and braking, slipping or spinning of the wheels) and dynamic loads (impact) formed between the wheel and the rail can assign the location of rail defect or irregularity. The dangerous track irregularities can be identified from the measured accelerations, which exceed the admissible acceleration limits [1], [22].

\subsection{Track gauge}

The track gauge can be estimated by detecting the rail-wheel flange contact caused vibration. During the realized line-tests the significant part of the track was grooved rail formed continuous elastic rail bed system. Depending on the one or two-point wheelrail contact the wheel has different vibration behavior: if the contact between the wheel and the rail occurs between the wheel flange back and the rail grooved head the vibration frequency is between $1.4-1.8 \mathrm{kHz}$, while, if the contact occurs between the flange and running head of grooved rail, the dominant vibration frequencies centered around $1500 \mathrm{~Hz}$. So that places, where the track gauge exceeds admissible limits, can be identified [23].

\section{Measured data, line-test results}

Preliminary testing of track condition assessment system was performed both in a tram depot and under the operating condition on the tram line 49 in Budapest. During both the measurements in tram depot and line test a GPS device was mounted on the top of the vehicle to ensure the continuous record of the position. The position information from GPS especially the distance and speed are recovered to compare the computed (by EKF) and the real covered distance. Fig. 4 shows the place of line test. The covered route of vehicle is signed by bold line. Part a) b) and c) in Fig. 4 illustrate track defects, which are observed during perambulation of this section.

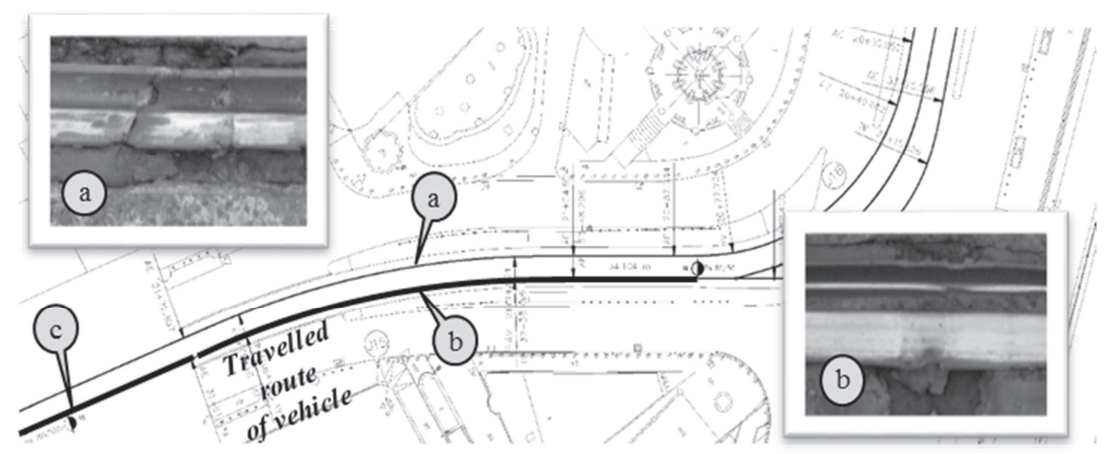

Fig. 4. Investigated track section, the horizontal plan at Saint Gellért Square in Budapest and the pictures of observed track defects 
Fig. 5 illustrates the results of this line test. During the test the accelerometers are mounted only on the not-driven wheels. First diagram in Fig. 5 illustrates the vehicle velocity, which are computed from the data of wheel mounted accelerometers using EKF (refer to Section 3.3).
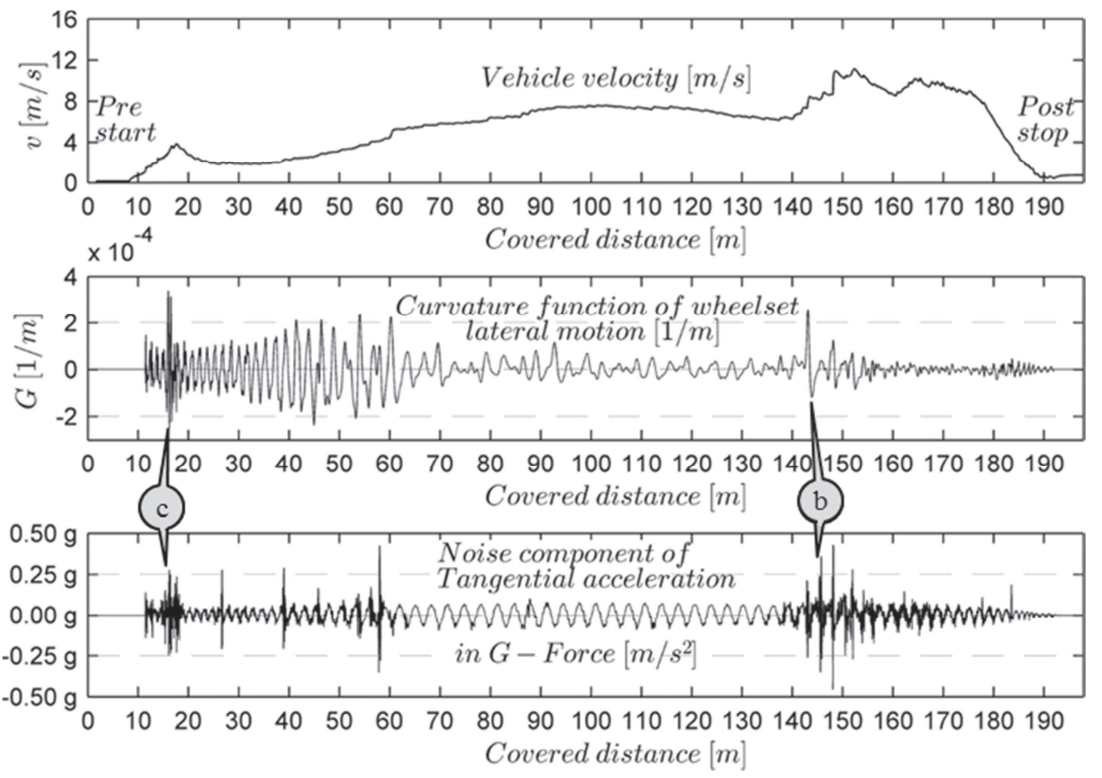

Fig. 5. Measurement results using in-service vehicle at Saint Gellért Square in Budapest (accelerometers are mounted on the not-driven wheels)

The measured $a_{z}$ axial acceleration is suitable to compute the lateral displacement of the wheel-set by using Frenet-Serret formulas, which describe the geometric properties (tangent, normal, and binormal unit vectors) of the curve itself irrespective of any motion. The curvature function $G(x, y)$ of wheel-set lateral motion can be computed from the following equation:

$$
a_{z}=v^{2} G(x, y)=v^{2} \frac{1}{\rho}
$$

where $a_{z}\left[\mathrm{~m} / \mathrm{s}^{2}\right]$ is the lateral (axial) acceleration; $v[\mathrm{~m} / \mathrm{s}]$ is the is the vehicle velocity; $\rho[\mathrm{m}]$ is the radius of curvature; $G(x, y)[1 / \mathrm{m}]$ is the curvature function in horizontal plane.

The second diagram in Fig. 5 shows the wheel-set lateral motion. After applying high-pass filter $(7 \mathrm{~Hz})$ or moving average on sensed data to remove signal form rotational motion the wheel-rail vibration can be computed. The third diagram in Fig. 5 presents the residual vibration acceleration ('noise') component of tangential 
acceleration. The peak values $b$ and $c$ in Fig. 5 refer to track defects, which are introduced in Fig. 4.

\section{Conclusion and further issues}

The track condition assessment model being currently developing is suitable to detect rail defect and after validation to predict defects too. Validation means to identify admissible limits of proper emerging loads of the peaked (accelerations) by collecting characteristics of measured acceleration data in the case of existing different track defects. It is important to note that the measured acceleration data were disturbed by significant noise, so the filtering of measured signal is necessary. For example: it is not allowed to filter the peak values, which can assign to the possible rail defects.

In the future, it is absolutely necessary to compare the precision and efficiency of the introduced experimental arrangement to the method based on signals of axle bearing-mounted accelerometers.

\section{Acknowledgements}

The Author intends to thank the Budapest Public Transport Ltd. (BKV) and METALELEKTRO Measuring Technique Ltd. for assuring of the tramcar and the inertial sensors as well as to Gy. Tóth for the helpful discussions on EKF.

\section{References}

[1] UIC CODE 518, Testing and approval of railway vehicles from the point of view of their dynamic behavior, safety - track fatigue - ride quality, International Union of Railway, Paris, France, 2005.

[2] Weston P., Roberts C., Yeo G., Stewart E. Perspectives on railway track geometry condition monitoring from in-service railway vehicles, Vehicle System Dynamics, International Journal of Vehicle Mechanics and Mobility, Vol. 53, No. 7, 2015, pp. 1063-1091.

[3] Kormos Gy., Barna Zs., Bocz P. Development of condition monitoring and assessment model for tramway track infrastructure (in Hungarian), Budapest University of Technology and Economics, Department of Highway and Railway Engineering, Research and Development project, 2004.

[4] Coenraad E. Modern railway track (Digital Edition 2014, version 3.1), Delft University of Technology, 2014.

[5] Jens N., Eric B., Thomas L., Roger M., Bert S., Lise P. Overview of methods for measurement of track irregularities important for ground-borne vibration, Railway Induced Vibration Abatement Solutions (RIVAS) Project, International Union of Railway, Brussels, Belgium, 2013.

[6] Veit P. Integrierte Gleisinstandhaltung, Zeitschrift für Eisenbahnwesen und Verkehrstechnik (ZEV) Rail Glasers Annalen, Vol. 129, No. 8, 2005, pp. 330-335.

[7] Maneiro A., Ocampo J. Using linear referencing \& dynamic segmentation to model linear assets, Innovation, Cooperation, Cartography and Territory S.L. (ICARTO) http://icarto.es/wp-content/uploads/iCarto_lrs.pdf. (last visited 3 September 2015) 
[8] Zobory I. Dynamics-measurement-certification of the track-vehicle system (in Hungarian), Közlekedéstudományi Szemle. Vol. 65, No. 1, 2015, pp. 6-19.

[9] Zobory I., Vilmos Z. On the dynamics of the railway track/vehicle system in the presence of inhomogeneous rail supporting parameters, $10^{\text {th }}$ Mini Conference on Vehicle System Dynamics, Identification and Anomalies VSDIA, Budapest, Hungary, 6-8 November 2006, pp. 117-122.

[10] Fischer Sz. Comparison of railway track transition curves, Pollack Periodica, Vol. 4, No. 3, 2009, pp. 99-110.

[11] Major Z. Special problems of interaction between railway track and bridge, Pollack Periodica, Vol. 8, No. 2, 2013, pp. 97-106.

[12] Danka M. Diagnostic and maintenance management systems of tramway rolling-stocks, (in Hungarian) Müszaki Könyvkiadó, Budapest, 1983.

[13] Gábor P. Measurement results of 8-axle GANZ type articulated tramcar (in Hungarian), Városi Közlekedés, Vol. 8, No. 4, 1968, pp. 313-341.

[14] Hitoshi T., Yasukuni N., Akira M., Takeshi M., Hirotaka M. Condition monitoring of railway track using in-service vehicle, Journal of Mechanical Systems for Transportation and Logistics, Vol. 3, No. 1, 2010, pp. 154-165.

[15] Daubechies I. The wavelet transforms time-frequency localization and signal analysis, IEEE Transactions Information Theory, Vol. 36, No. 3, 1990. pp. 961-1005.

[16] Zobory I., Békefi E., Zábori Z. Simulation backed identification of vertical track stiffness function by using wavelets, $6^{\text {th }}$ Mini Conference on Vehicle System Dynamics, Identification and Anomalies VSDIA, Budapest, Hungary, 9-11 November 2000, pp. 151-159.

[17] Mallat S. G. A theory for multiresolution signal decomposition: the wavelet representation, IEEE Transactions on Pattern Analysis and Machine Intelligence, Vol. 11, No. 7, 1989. pp. 674-693.

[18] Vinkó Á. Tramway track diagnostic method using wheel-mounted inertial sensors, $20^{\text {th }}$ International Seminar Track Maintenance Machines in Theory and Practice SETRAS 2014, Zilina, Slovakia, 4-6 November 2014, Vol. 1, pp. 153-160.

[19] Kalman R. E. A new approach to linear filtering and prediction problems, ASME, Journal of Basic Engineering, Vol. 82, No. 1, 1960. pp. 35-45.

[20] Bernd G., Udo F. A Kalman-filter for odometry using a wheel mounted inertial sensor, $10^{\text {th }}$ International Conference on Informatics in Control, Automation and Robotics, Reykjavík, Iceland, 29-31 July 2013, pp. 388-395.

[21] Simonyi E. Digital filters, (in Hungarian) Müszaki Könyvkiadó, Budapest, 1984.

[22] Wilson A. Rail defects handbook, Engineering Manual, Rail Corporation, New South Wales (NSW), 2012.

[23] R. Corradi, P. Crosio, S. Manzoni, G. Squicciarini. Experimental investigation on squeal noise in tramway sharp curves, Proceedings of the $8^{\text {th }}$ International Conference on Structural Dynamics, EURODYN, Leuven, Belgium, 4-6 July 2011, pp. 3214-3221. 